\title{
Cortisol concentration in the saliva of horses subjected to different kinds of exercise
}

\author{
Katarzyna Strzelec ${ }^{1}$, Marta Kankofer ${ }^{2}$, Sławomir Pietrzak ${ }^{1}$ \\ ${ }^{1}$ Department of Horse Breeding and Use, Faculty of Animal Biology and Breeding, \\ ${ }^{2}$ Department of Animal Biochemistry and Physiology, Faculty of Veterinary Medicine, \\ University of Life Science in Lublin, Poland
}

Received July 20, 2009

Accepted September 21, 2010

\begin{abstract}
The aim of this study was to characterize the stress level in sport horses subjected to exercise by measuring the cortisol concentration in their saliva. The experiment was conducted on 5 groups of horses (49 animals): one control and four groups undergoing different types of exercises. The saliva samples were collected $3 \times$ a day: late at night (between 20:00 and 23:00 h), early in the morning (between 5:00 and 8:00 h) and directly after the exercise. The concentration of cortisol was measured by the enzyme-immunoassay programme. The highest cortisol concentration was observed for the horses participating in 3-day events (8.93 $\mathrm{nmol} / \mathrm{dm}^{3}$ ), whereas in the control group it was only $0.28 \mathrm{nmol} / \mathrm{dm}^{3}$. When compared to the cortisol concentration of other horse groups, this suggests that the stress level as measured by the cortisol concentration in saliva increases with increasing exercise intensity and its duration. The obtained results do not confirm the existence of a day rhythm of the cortisol concentration in horses. Moreover, the results may help in choosing the appropriate system of training and in improving horse welfare during competitions.
\end{abstract}

Effort, equestrian disciplines, stress, sport horses

Stress is related to biochemical reactions leading to the formation of substances that are commonly described as indicators of the stress level. These indicators are responsible for the restoration of homeostasis. One of the main substances that indicate stress level is cortisol which is a natural glucocorticoid hormone produced by the adrenal cortex. Cortisol has many general as well as metabolic functions, including a significant influence on the metabolism of carbohydrates, proteins and fats. The concentration of cortisol depends on the natural circadian rhythm, which can be disturbed by physical as well as mental stress. The cortisol concentration in blood serum is the highest between 6:00 and 8:00 h and the lowest between 23:00 and $4.00 \mathrm{~h}$ (Hoffis et al.1970; Lindner et al. 1990). However, cortisol concentration can increase even ten-fold as a result of stress (Ślebodziński 1979; Hartwig 1989). Cortisol can be found not only in the blood serum but also in other body fluids including body excrements (Mostl and Palme 2002).

Cortisol secretion and its concentration in plasma depend strictly on adrenocorticotrophin which significantly increases when the sympathetic nervous system is stimulated especially under stress or in inflammatory states. Its catabolic function leads to an increase in the turnover of skeleton muscle protein. It does this by stimulating the disintegration and slowing down the synthesis, which can result in losing muscle tissue. Catabolic function also boosts the glucose production from the amino acids coming from protein disintegration. Cortisol can enhance and prolong the effects of other hormones including the adrenergic ones.

However, the determination of cortisol concentration in animal serum is not always possible and taking blood samples causes additional stress. For this reason, easier and less invasive methods have been invented that make use of saliva, urine and faeces.

Phone: +48814456575

Fax: +4881533 3752

E-mail: kasia.strzelec@poczta.fm

http://www.vfu.cz/acta-vet/actavet.htm 
The most effective way of determining cortisol concentration in animals seems to be by using their saliva. This is because taking saliva samples is a rather simple, non-invasive and low-stress procedure (Aardal and Holm 1995). Moreover, the rate of balancing the cortisol concentration in saliva and blood is rapid: the whole process takes less than 5 min. For these reasons, determining the level of cortisol using saliva is a more advantageous way of examining the adrenal cortex functions than using blood serum (Vining et al. 1983). Therefore, the saliva testing is selected as the method of choice for sport horses. Such horses must often undergo testing during their competition periods in stressful conditions. Their saliva sampling is convenient as it does not require any special treatment and the samples can be stored at room temperature for up to 7 days (Aadral and Holm 1995; Clements and Parker 1998). Sport horses are used in a variety of sport disciplines which require different preliminary physical work and exercise during competition, and hence impose different stress intensities. These disciplines can be grouped by how intense the work is, for example: dressage, endurance, show jumping, three day event and races. However, we need a relationship between such different stress intensities and the cortisol concentration in horse saliva.

The aim of this study, therefore, is to estimate the intensity of the stress level in sport horses as a function of exercise intensity by measuring the cortisol concentration in their saliva.

\section{Materials and Methods}

This study was based on 5 groups of horses $(n=49)$ doing different types of exercise. The first group was the control group of 10 horses ( 5 of the Małopolska breed, 3 of the Polish noble half breed, 1 Wielkopolska breed and 1 pony) aged from 4 to 20 years. The control group of horses spent time in the paddock doing no special exercise. The second group of 9 horses ( 4 of the Małopolska breed, 3 of the Polish noble half breed, 1 Wielkopolska breed and 1 pony) aged from 4 to 16 years was exposed to light exercise (walk, trot) for 4 to 6 $\mathrm{h}$ a day. The other three groups (each of 10 animals) represented different disciplines such as dressage, show jumping and three days events. Within each group there were animals of different breeds but approximately the same age ( 5 years). These 3 groups took part in the 2008 Polish Horses Championships For Young Horses in Książ, Łąck and Biały Bór. Their saliva samples were collected $3 \times$ a day: late at night (between 20:00 and 23:00 h), early in the morning (between 5:00 and 8:00 h) and right after the exercise. In the control group the samples were collected four times a day. All the saliva samples were collected with a small piece of sponge $(2 \mathrm{~cm} \times 2 \mathrm{~cm})$ soaked in $1 \%$ acetic acid and dried at room temperature (as described by Pell and McGreevy 1999). Using metal tweezers, the sponge was inserted into the horse's mouth and rubbed against the animal's tongue, inner cheeks and palate. The sponge soaked in saliva was then placed in a centrifugation tube. Each tube had a $2 \mathrm{~cm}$ long piece of plastic straw preventing the sponge from touching the bottom of the tube and absorbing the saliva during the centrifugation. Next, all the samples were frozen. This allowed their storage in an unchanged physical and biological state.

Before examination the sample was melted, warmed up to room temperature and centrifuged in MPW 211 at $500 \times g$ for $15 \mathrm{~min}$ at room temperature. Next, the sponge and the straw were removed and the saliva was transferred to Eppendorf test tubes. The coritsol level measurement was conducted with the enzyme-immunoassay using the CORTISOL EIA kit (for saliva) DSL_10-67100 made by Diagnostic System Laboratories Inc., USA. The absorbance level measurement was conducted at 450 and $620 \mathrm{~nm}$ wavelength using a Multiscan reader (Labsystems, Helsinki) equipped with a GENESIS V 3.00 programme. The results were expressed in $\mathrm{nmol} / \mathrm{dm}^{3}$.

Statistical analysis

The cortisol concentration determinations were duplicated. The results were processed using a STATISTICA 6.0 package based on the one-way analysis of variance. The differences between the group averages and the circadian rhythm data within each group were estimated from Fischer's LSD.

\section{Results and Discussion}

The control group of horses was not under the influence of any stress factors that could significantly change the cortisol concentration in their saliva. This was confirmed by all the data taken at different times of the day $(20: 00 \mathrm{~h}, 7: 00 \mathrm{~h}, 17: 00 \mathrm{~h}, 22: 00 \mathrm{~h})$, namely the mean cortisol concentration usually did not exceed $0.45 \mathrm{nmol} / \mathrm{dm}^{3}$ (Table 1 ) and for the majority 
Table 1. Statistical characteristic of salivary cortisol concentration $\left(\mathrm{nmol} / \mathrm{dm}^{3}\right)$ in examined groups of horses.

\begin{tabular}{lccccccc}
\hline \multirow{2}{*}{ Group } & \multirow{2}{*}{ Number } & \multicolumn{2}{c}{ Late evening } & \multicolumn{2}{c}{ Early morning } & \multicolumn{2}{c}{ After exercise } \\
\cline { 2 - 7 } & & Mean & SD & Mean & SD & Mean & SD \\
\hline Control & 10 & $0.45 \mathrm{~A}$ & 0.57 & $0.49 \mathrm{~A}$ & 0.74 & $0.28 \mathrm{~A}$ & 0.00 \\
$\begin{array}{l}\text { Recreational } \\
\text { (Light exercise) }\end{array}$ & 9 & $0.55 \mathrm{~A}$ & 0.58 & $0.29 \mathrm{~A}$ & 0.05 & $0.74 \mathrm{~A}$ & 1.39 \\
$\begin{array}{l}\text { Sport } \\
\text { Show jumping) }\end{array}$ & 10 & $3.45 \mathrm{~B}$ & 4.92 & $2.43 \mathrm{~B}$ & 2.89 & $3.98 \mathrm{~B}$ & 5.94 \\
$\begin{array}{l}\text { Sport } \\
\text { (Three day events) }\end{array}$ & 10 & $0.77 \mathrm{AA}^{،}$ & 1.58 & $0.81 \mathrm{ABA}$ & 1.71 & $8.39 \mathrm{CB}^{\star}$ & 4.36 \\
Sport (Dressage) & 10 & $0.43 \mathrm{~A}$ & 0.41 & $1.41 \mathrm{AB}$ & 1.89 & $0.71 \mathrm{~A}$ & 0.29 \\
\hline
\end{tabular}

A, B, C... Significant differences at $p<0.01$ (in columns)

$\mathrm{A}^{*}, \mathrm{~B}^{`} \ldots$... Significant differences at $p<0.01$ (at lines)

of horses individual values were below $0.276 \mathrm{nmol} / \mathrm{dm}^{3}$ which is the detection limit, except for two individual cases of two different animals $\left(2.18 \mathrm{nmol} / \mathrm{dm}^{3}\right.$ and $2.73 \mathrm{nmol} / \mathrm{dm}^{3}$ at 20:00 $\mathrm{h}$ and 7:00 $\mathrm{h}$, respectively).

These results are consistent with those of Larrson et al. (1979) and Harewood and McGowan (2005), who observed no or hardly any circadian rhythm of cortisol concentration for such horses, but not with those of Moons et al. (2002) and Irvine and Alexander (1994) who observed a circadian rhythm.

A similar result was observed for the light-exercise group of horses: their mean cortisol concentration was found to be up to $0.55 \mathrm{nmol} / \mathrm{dm}^{3}$ and usually below 0.276 $\mathrm{nmol} / \mathrm{dm}^{3}$ (Table 1). In one of the evening testings, high concentrations of cortisol $\left(1.93,1.10\right.$ and $\left.4.47 \mathrm{nmol} / \mathrm{dm}^{3}\right)$ were recorded in three animals. These data were discarded as stress-unrelated aberration. Moons et al. (2002) measured the average cortisol concentration in the saliva of 3-month-old Arabian foals divided into 3 control groups to be around $2.6 \mathrm{nmol} / \mathrm{dm}^{3}$ in the morning and $1.3-1.6 \mathrm{nmol} / \mathrm{dm}^{3}$ in the evening, which is similar to the data reported by Van der Kolk et al. (2001), which ranged from $1.38 \mathrm{nmol} / \mathrm{dm}^{3}$ to $2.27 \mathrm{nmol} / \mathrm{dm}^{3}$.

In a study conducted by Harewood and McGowan (2005) on 2-year-old mares (Australian Stock) in the paddock and stables, the average cortisol level was $5.52 \mathrm{nmol} / \mathrm{dm}^{3}$ (in the paddock group) and $6.90 \mathrm{nmol} / \mathrm{dm}^{3}$ (in the stable group). These results are similar to results (from 4.14 to $9.66 \mathrm{nmol} / \mathrm{dm}^{3}$ ) obtained by Pell and McGreevy (1999) for the trained thoroughbred horses aged from 1 to 6 years which exhibited irregular behavior (crib-biters, wind-suckers, weavers, box-walkers).

In the research conducted on other kinds of animals, the concentration of cortisol in the saliva significantly increased under the influence of stress factors. Fell and Shutt (1986) and Cooper et al. (1998) examined the influence of confinement and transport of sheep and cattle on cortisol concentration and the results were $19.8 \mathrm{nmol} / \mathrm{dm}^{3}$ and $5.24 \mathrm{nmol} / \mathrm{dm}^{3}$, respectively.

While analyzing the cortisol concentration in sport horses undergoing different types of exercise, it was discovered that the level of cortisol late at night was different. The horses taking part in dressage exhibited a similar mean concentration of cortisol to the two previous groups $\left(0.43 \mathrm{nmol} / \mathrm{dm}^{3}\right)$. In the evening, their cortisol concentration was slightly higher and reached $0.77 \mathrm{nmol} / \mathrm{dm}^{3}$ (Table 1). Despite different surroundings (the horses took part in the competition and stayed in unfamiliar stables), the animals did not show any signs of stress. A different situation was observed for a group of show jumping horses. Their evening cortisol concentration was about $3.45 \mathrm{nmol} / \mathrm{dm}^{3}$, which is significantly 
higher in comparison to the other groups $(p<0.01)$. A similar tendency was observed in the morning measurements $\left(2.43 \mathrm{nmol} / \mathrm{dm}^{3}\right)$. However, in this case, significant differences were only observed compared to the control group and the recreational (light-exercise) group. The horses taking part in dressage also showed an increased morning cortisol concentration $\left(1.41 \mathrm{nmol} / \mathrm{dm}^{3}\right)$ compared to the evening cortisol concentration $\left(0.43 \mathrm{nmol} / \mathrm{dm}^{3}\right)$ (Table 1).

For the horses taking part in the 3-day events, no significant differences between their evening and morning cortisol concentrations were detected. In both cases, it was lower than $1.0 \mathrm{nmol} / \mathrm{dm}^{3}$, which confirms a lack of the circadian rhythm.

The mean cortisol concentration in show jumping horses examined after the exercise was $3.98 \mathrm{nmol} / \mathrm{dm}^{3}$ in a wide range from 0.276 to $19.9 \mathrm{nmol} / \mathrm{dm}^{3}$ which can be explained by a greater individual variability in this group (Table 1). The low concentration of the stress hormone in some cases may be due to the short exercise duration (about $1 \mathrm{~min}$ ), as reported by Hyyppa (2002). He claims that the increase of the cortisol concentration in plasma reflects the duration of exercise better than its intensity. Since the rate of cortisol being released from the adrenal cortex is rather slow, the duration of exercise on the parcour might not be sufficient to reflect the real level of the hormone. According to Jimenez et al. (1998) and Nagata et al. (1999), the cortisol level during short exercise is not related to its intensity, and the cortisol maximum concentration in plasma can be observed 5-30 min after short but intensive exercise. However, some horses can exhibit an increased cortisol concentration even before the exercise. Many experts agree that this is because age, breed, previous experience and changing surroundings can significantly influence the basic cortisol concentration (Linden et al 1991; Harewood and McGowan 2005).

The highest cortisol concentration was observed after exercise $\left(8.39 \mathrm{nmol} / \mathrm{dm}^{3}\right)$ $(p<0.01)$ in the group of horses taking part in 3-day events (Table 1). This suggests that extensive physical exercise to which the horses are exposed as well as its duration significantly increase the stress level (Jimenez et al. 1998; Mostl and Palme 2002). For the control, recreational and dressage groups, there were no major differences in the cortisol concentration after exercise; it ranged between 0.27 and $0.74 \mathrm{nmol} / \mathrm{dm}^{3}$ (Table 1).

The research done on people undergoing different physical exercise also exhibited a close relationship between the intensity and the duration of the exercise (Branderberger and Follenius 1982). Similar tendencies were observed in the research based on cortisol concentration in plasma. According to Jimenez et al. (1998), the concentration of this hormone in horse plasma is related to the intensity and duration of the effort.

Nogueira and Barnabe (1997) determined the cortisol concentration in the plasma of racing mares aged from 1 to 4 years and found significant differences between age groups, for example $148.8 \mathrm{nmol} / \mathrm{dm}^{3}$ (1-2 years), $125.7 \mathrm{nmol} / \mathrm{dm}^{3}$ (2-3 years) and $101.1 \mathrm{nmol} / \mathrm{dm}^{3}$ (3-4 years). The lowest concentration was observed in the oldest horses. This can be explained by the fact that stress, if lasting for a longer period, can become chronic and hence result in a reduction of hypophyseal corticotrophin releasing hormone receptors.

A series of experiments was also conducted to discover a connection between the cortisol concentration in plasma and saliva. According to Moons et al. (2002), the correlation coefficient between saliva and plasma was $r=0.41(p<0.1)$, whereas that between saliva and serum was $r=0.52$ and in this case it was significant $(p=0.0306)$.

Aadral and Holm (1995) found that the relationship between the concentration of cortisol in serum and in saliva was not linear. The correlation coefficient was $r=0.86$ for the concentration in serum $<450 \mathrm{nmol} / \mathrm{dm}^{3}$ and $\mathrm{r}=0.44$ in saliva $\geq 450 \mathrm{nmol} / \mathrm{dm}^{3}$. According to the authors, their results suggest that saliva can be used instead of blood in cortisol concentration determination.

No circadian rhythm affecting cortisol concentration was observed in most of the horse 
groups. Only the horses taking part in 3-day events seemed to be influenced by it. The cortisol concentration, as expected due to intensive stress conditions, was significantly higher after the exercise $(p<0.01)$ compared to the morning and evening levels (Table 1$)$.

In conclusion, the highest cortisol concentration was observed in the horses participating in 3-day events compared to control horses and horses doing other activities. The stress level as measured by the cortisol concentration in saliva increases with increasing exercise intensity and its duration. Short exercise does not produce a real reaction to stress, which suggests that the saliva samples can be collected after a longer period following an exercise.

\section{Acknowledgment}

The authors are pleased to thank Prof Maciej Radosz of University of Wyoming for his helpful comments and proof-reading.

\section{References}

Aadral E, Holm AC 1985: Cortisol in saliva - references ranges and relation to cortisol in serum. Eur J Clin Chem Clin Biochem 33: 927-932

Brandenberger G, Follenius M 1982: Influence of timing and intensity of muscular exercise on temporal patterns of plasma cortisol levels. J Clin Endocrinol Metab 54: 592-596

Clements AD, Parker CR 1998: The relationship between salivary cortisol concentrations in frozen versus mailed samples. Psychoneuroendocrinology 23: 613-616

Cooper TR, Trunkfield HR, Zanella AJ, Booth WD 1989: An enzyme linked immunosorbent assay for cortisol in the saliva of man and domestic animals. J Endocrinol 123: R13-R16

Fell LR, Shutt DA 1986: Use of salivary cortisol as an indicator of stress due to management practices in sheep and calves. Proc Aust Soc Anim Prod 16: 203-206

Harewood EI, McGowan CM 2005: Behavioral and physiological responses to stabling in Naive Horses. J Equine Vet Sci 4 164-170

Hartwig W 1989: Endokrynologia praktyczna (Practical Endocrinology). Państwowy Zakład Wydawnictw Lekarskich. Warszawa, 538-576

Hoffis G, Murdick P, Tharp V, Ault K 1970: Plasma concentration of cortisol and corticosterone in the normal horse. Am J Vet Res 31: 1379-1387

Hyyppa S 2002: Endocrinal responses and regulation in exercising horses. Book of Abstracts of the $53^{\text {rd }}$ Annual Meeting of European Association for Animal Production No 8, Cairo, 270 p.

Irvine $\mathrm{CH}$, Alexander SL 1994: Factors affecting the circadian rhythm in plasma cortisol concentration in the horse. Domest Anim Endocrinol 11: 227-238

Jimenez M, Hinchcliff KW, Harris JW 1998: Catecholamine and cortisol responses of horses to incremental exertion. Vet Res Commun 22: 107-118

Larrson M, Edqvist LE, Ekman L, Person S: 1979 - Plasma cortisol in the horse, diurinal rhythm and effects of exogenous ACTH. Acta Vet Scand 20: 16-24

Linden A, Art T, Amory H, Desmecht D, Lekeux P 1991: Effect of 5 different exercise, transportation and ACTH administration on plasma cortisol concentration in sport horses. Equine Exercise Physiology 3. ICEEP Publications, Davis, California, pp. 391-396

Lindner A, Will Y, Chrispeels J 1990: Reference values for cortisol, T4 and T-uptake in different horse groups using the fluorescence polarization immunoassay (FPIA). Berl Munch Tierarztl Wochenschr 103: 411-416

Moons C, Heleski CR, Leece CM, Zanella AJ 2002: Conflicting results in the association between plasma and salivary cortisol level in foals. Proceedings of the Dorothy Russel Havemeyer Foundation Workshop "Horse Behavior and Welfare". Holar College te Holar, Ijsland

Mostl E, Palme R 2002: Hormones as indicators of stress. Domest Anim Endocrinol 23: 67-74

Nagata S, Takeda F, Kurosawa M, Hiraga A, Kai M, Taya K: 1999: Plasma adrenocorticotropin, cortisol and catecholamines response to various exercise. Equine Vet J Suppl 30: 570-574

Nogueira GP, Barnabe RC 1997: Is the thoroughbred race-horses under chronic stress? Braz J Med Biol Res 30: $1237-1239$

Pell SM, McGreevy PD 1999: A study of cortisol and beta-endorphin levels in stereotypic and normal Thoroughbreds. Appl Anim Behavr Sci 64: 81-90

Ślebodziński A 1979: Zarys endokrynologii zwierząt użytkowych (Endocrinology of Farm Animals). PWN, Warszawa, 207-247

Van Der Kolk JH, Nachreiner RF, Scott HC, Refsal KR, Zanella KJ 2001: Salivary and plasma concentration of cortisol in normal horses and horses with Cushing's disease. Equine Vet J 33: 211-213

Vining RF, McGinley RA, Maksvytis JJ, Ho KY 1983: Salivary cortisol: A better measure of adrenal cortical function than serum cortisol. Ann Clin Biochem 20: 329-335 